\title{
JAVIER GARCÍA-BELLIDO Y EL PAISAJE AGRARIO SAYAGUÉS
}

\author{
Esther Isabel Prada Llorente \\ Dr. Arquitecto, Universidad SEK, \\ Segovia, España
}

Remisión Artículo: 6-2-2007

Palabras Claves: Tierra de Sayago, Núcleos de doblamiento ganadero, Fondo etimológico Sayago.

Resumen: Nos adentra en la morfología de los núcleos de poblamiento ganaderos de Tierra de Sayago, que Javier entendió como el "coto redondo acasarado" utilizado por Cerdá como base de la colonización en su "Teoría General de la Rurización", y en el fondo etimológico de esa zona.

El día 10 de marzo de 2006 se marchó Javier. Dos o tres días antes habíamos estado repasando las correcciones para la próxima publicación de otra parte de mi tesis doctoral en su revista Ciudad y Territorio: "Paisaje agrario: antropología de un territorio, II".

Nos despedimos casi como siempre, él hablando por teléfono muy excitado fijando fechas para próximas conferencias en la Escuela de Arquitectura de Barcelona y yo, diciéndole adiós con la mano a través de la ventana de su despacho, dejándole con su hiperactividad vital.

Derrochaba simpatía y me había pedido para él, una separata de la primera parte de la memoria doctoral que publicó en CyTET con una dedicatoria que tristemente no le llegué a entregar, aunque si pensé en lo que le hubiera escrito: "Para el arquitecto, perdón, urbanista más simpático que conozco". No le gustaba que le llamaran arquitecto, decía que no lo era, él se pensaba siempre como urbanista.

Entre la multitud de trabajos de investigación el último, que ocupaba prácticamente la totalidad de su tiempo y que tuve el honor de comenzar con él una mañana en Segovia, fue la trascripción de la ingente documentación del s. XIX conservada en el Archivo Militar relativa al derribo de las murallas de Barcelona. Más adelante, pensaba continuar con el resto de ciudades españolas que figuran en los legajos de este archivo.

Sacar a la luz lo que nadie sabía que existía, documentación escrita y cartográfica, en la que según afirmaba, radica todo el origen del urbanismo español, ordenando, explicando y transcribiendo, era la tarea fundamental que se había propuesto.

El puente del primero de mayo había previsto ir a Tierra de Sayago, mi tierra, comarca sita al SO de la provincia de Zamora en la frontera con Portugal. Había estado ya allí, dos veranos antes yendo de camino hacia Castropol y curiosamente en un pueblo Escuadro, que no tiene más de treinta de habitantes, no pudimos coincidir. No le pude explicar "in situ", que era lo que él quería, la configuración dispersa de los núcleos de poblamiento, ni la organización comunal de la propiedad de la tierra, ni dimos un paseo hasta la "dehesa", por eso había pensado ir el puente de mayo. 
A Javier le interesaban sobremanera, como casi todo, las tipologías de los núcleos ganaderos de toda esta zona fronteriza, su génesis, su desarrollo y su relación con el urbanismo de Cerdá. Curiosamente y aunque parezcan en principio temas tan dispares, así como ámbitos geográficos tan alejados, fue en la "unidad básica de aprovechamiento agrícola sayaguesa" o "heredad" donde encontró el origen de lo que constituía según el pensaba, el "coto redondo acasarado" entendido por Cerdá como el elemento base de la colonización dentro de su Teoría General de la «Rurización» (cfr. GARCíA-BELLIDO, 2004) y que según costumbre de Sayago estaba constituida por: una casa, un herreñal, un prado, un huerto y una tierra de pan llevar.

Las morfologías de los núcleos de poblamiento ganaderos de Sayago reflejan aún hoy en día, esa estructura ancestral de colonización del territorio con sus cercas y "paredes" de piedra antiquísimas, siempre con formas curvadas nunca en ángulo recto para una mejor adecuación al tránsito de carros y ganado, aspecto que Javier consideraba característico de la organización en planta de dichos núcleos.

La sucesión de escalas territorial, urbana y arquitectónica en tanto que categorías del "sistema paisaje agrario", definen el caleidoscopio que supone la multitud de aspectos que significan la imagen de Tierra de Sayago, haciéndola comprensible a través de las situaciones análogas que se establecen entre todas y cada una de las escalas, tal es el caso de los espacios comunales (cfr. PradA, 2005), pero también, mediante el conocimiento de factores antropológicos y sociales reflejados en el lenguaje o dialecto sayagués, que aportan datos muy valiosos para establecer cuál ha sido la evolución de su paisaje entendido como síntesis territorial.

Javier, interesadísimo como en tantos otros temas por las palabras y su origen, estuvo descifrando conmigo muchos de los significados de los términos utilizados en esta comarca "rayana" con Portugal, hallando similitudes con los utilizados por Cerdá en su Indicador Urbano que publicó en el número 144 de CyTET como homenaje a Juan Ramón Lodares "uno de los temas que vimos mas le preocupara al final de su vida, como muy recursivo e insistente, fue el de la filología y la estructura de la lingüística, con una referencia que aparecía en su Diario del 14 de junio de 1875 y un largo escrito que llevaba el sonoro nombre de "Clave racional de la estructura de la palabra", fechado el 19 de junio de 1876... Pero, no obstante, el interés de Cerdá por las palabras lo había expresado extensa y densamente en El Indicador urbano insertado en la Teoría General de la Urbanización (1867)" (GARCíA-BELLIDO, 2005).

Las plantas cultivadas, la propiedad de la tierra o la organización del terrazgo, han variado fuertemente aún en comarcas que parecen estacionadas, tal es el caso de Tierra de Sayago pero, para la explicación del paisaje agrario actual y su conservación a largo plazo, es indispensable investigar sobre el pasado, por eso creo de suma utilidad, consultar todas aquellas fuentes que son indispensables para la historia del paisaje agrario español, tal es el caso de filologías y etimologías propias del mundo rural transmitidas de forma oral, siguiendo a modo de indicador rural o guía del viajero las pautas de Cerdá y del propio Javier GarcíaBellido.

Fue la persona que después de mi padre, más se interesó por esta zona fronteriza, las características de su paisaje y la descripción que del mismo había realizado en mi memoria doctoral. Javier fue el que se arriesgó por sacarla a la luz y también el mejor profesor que se 
puede tener, escuchando y otorgando todo su conocimiento sin reservas. Dentro del fondo etimológico transmitido de forma oral cuál es el lenguaje del quehacer diario sayagués voy a relatar en estas líneas aquellos vocablos que más llamaron su atención durante los tres años que tuve la suerte de compartir con él el paisaje de mi infancia, Sayago, una geografía muy especial del medio rural español.

\section{GLOSARIO}

ABALEADERA: Escoba para barrer el corral o la era, realizada con una planta o matorral denominado baleo.

ALBAÑAL: Zanja para evacuación de aguas sobrantes fundamentalmente en las cortinas, de $70 \mathrm{u} 80 \mathrm{~cm}$ de profundidad rellena de cantos o jejos cubiertos con pajas generalmente de centeno y una capa exterior de arena.

ALCOBA. Dormitorio asociado a una sala únicamente separada de ésta la cama, constituyendo la "unidad de habitación" la sala y las alcobas.

APAJAR: Dar de comer al ganado la paja recolectada.

ARICAR: Arar por segunda vez sobre los surcos ya realizados para airear la raíz de la planta.

ARRASTRAR: Descabezar los cerros una vez realizada la siembra.

ARTESA: Gran recipiente o barreño de madera utilizado generalmente para amasar.

AVENTAR: Separar el grano de la paja una vez trillada la mies.

BARDAL: Barda, quejigo, roble, monte bajo.

BARRILA: Recipiente de barro de dos asas más pequeño que la cántara.

BARZÓN: Anilla de madera que forma parte del yugo y que sujeta el cambizo.

BIELDA: Especie de rastrillo de madera de picos planos utilizado para juntar la paja y el grano en un montón una vez realizada la trilla.

BIELDO: Más pequeño que la bielda. Se utiliza para aventar o "limpiar", es decir separar el grano de la paja.

BURACO: Abertura situada en las partes más bajas de los cerramientos exteriores de las construcciones para el paso de animales (gatos, gallinas, perros) desde la calle a los corrales.

CABRIO: Palo de encina o roble que constituye la estructura base de formación de pendientes en una cubierta.

CALDERA: Recipiente de cobre utilizado generalmente en las matanzas para cocer las morcillas.

CALDERO: Más pequeño que la caldera, se suele colgar de los llares en la lumbre para procurarse agua caliente.

CAMBIZO: Viga de madera que se une al trillo a través del trépago en un extremo y en el otro con el yugo de la pareja generalmente de vacas sayagasesas, utilizadas para la trilla.

CÁNTARA: Recipiente de barro de capacidad medio cántaro con dos asas.

CÁNTARO: Recipiente de barro de un asa.

CAÑIZO: Entramado de hojas y ramas de roble o encina situado sobre los cabrios y debajo de las tejas en una cubierta.

CARRETERA: Construcción que flanquea los corrales con aberturas a los mismos denominadas "bocas" para guarda de ganado. 
CARRETERO. Construcción independiente para la guarda del "carro".

CERNIDERO: Construcción aneja a la vivienda. Lugar donde se amasaba y se hacía el pan.

CERRO o CUETO: Superficie elevada de tierra resultado de la penetración del arado. Teso

COBERTERA: Piedra de remate o terminación de una pared.

COMEDERO. Construcción aneja a la vivienda para dar de comer al ganado.

CORRAL: Patio enlosado con cantos o "jejos" en torno al que se sitúan tanto la vivienda como las dependencias anejas a la misma a través del que se realizan todos los accesos.

CORREDOR. Galería abierta situada en el sobrado para entrada de luz y guarda de alimentos.

CORTINA. Cohorte o unidad de explotación agrícola medieval de propiedad privada y cercada con pared de piedra. Probablemente del latín cohors-tis. Se siembra "a cerro" para cultivo de cereal. Normalmente situada en el entorno del casco urbano. El conjunto de cortinas se denomina cortineo o cortiñedo y las situadas de forma esporádica en las tierras comunales se denominan casales.

CORTINO. Parcela cercada con pared de piedra de menor superficie que la cortina y muy próximo a la vivienda. Tipo de siembra "a manta" para "segar de verde" para el ganado. El masculino es utilizado en Sayago de forma un tanto despectiva.

COSTAL. Saco de lana para guardar cereal.

COTO. Piedra esquinera para señalización de límite de parcela.

ESCUADRO (TOPÓNIMO). Aldea de la comarca de Sayago. Es-CUADRO. Algún tipo de parcelación romana. Ex-CUADRO. Asentamiento "fuera del cuadro". Es-QUADRO. Denominación medieval del mismo núcleo de poblamiento.

CUMBRE. Pared o cerramiento exterior de una vivienda o construcción generalmente sin huecos, ubicada bajo la cumbrera y dos aguas de la cubierta.

CHOZO. Caseta de pastores por lo general de forma circular construida en piedra y situada en las tierras abiertas.

DEHESA. Del latín deffesa. Finca cerrada y cercada "en coto redondo", es decir todo en torno a ella.

DERROTA (DE MIESES). Una vez segada la hoja correspondiente al cultivo de un año convertir tanto la hoja incultivada o barbechera como el rastrojo de la cultivada, en pasto para el ganado del común de vecinos.

ERA. Tierra inculta destinada a la trilla.

ESGARRAR. Hacer montones más pequeños de un muladar o mudadal y esparcirlos como abono antes de la siembra.

HERRADA. Cubo de zinc.

HINCÓN. Piedra hincada. Parte de la estructura de composición de una pared de piedra.

HOJA. Partición de un término municipal en zonas para cultivo y barbecho según un sistema de rotación que puede ser bienal o trienal.

HUERTO. Pequeña tierra cercada y muy próxima a las viviendas para cultivo de legumbres y hortalizas.

JEJO. Piedra pequeña o "canto" para solar los corrales o rellenar albañales.

JERA. Trabajo comunal (arreglo de caminos, recolección de bellota, reparto de leña, etc.).

LANCHA. Piedra de grandes dimensiones para solar portales, interiores de vivienda. 
LINDE. Surco incultivado entre tierras de labor de diferentes propietarios.

LONGUERO. Parcela larga y estrecha que aprovecha dentro de su perímetro distintas calidades de tierras.

LLAR. Cadena metálica situada en las chimeneas de la que se cuelgan herradas o calderos.

MANCERA. Barra de madera con la que se maneja el arado.

MONDAR. Limpiar las dependencias para el ganado.

MUELO. Montón de grano (trigo, cebada o centeno) una vez separado de la paja.

NAVA. Valle.

NEGRILLO. Olmo. En Sayago prácticamente desaparecidos. Antiguamente existía en casi todas las plazas de los pueblos alrededor del cual se reunía el concejo.

NIAL. Lugar de puesta de huevos.

OCHAVA. Recipiente de madera con uno de sus extremos terminado en cuña, que constituye una medida de peso de cereal. También constituyen medida de peso los correspondientes recipientes de madera referidos a, "media ochava" (tres celemines) igual que el anterior pero más pequeño y medio celemín.

PAJAR. Construcción aneja a la vivienda para guardar la paja.

PANERA. Construcción independiente o adosada como dependencia aneja a la vivienda, para guarda de harina resultado de la molienda del cereal recolectado para alimento del ganado.

PARDAL. Gorrión.

PARED. Separación de fincas particulares o "cortinas" realizada en piedra.

PARVA. Montón de haces.

PIORNO. Escoba pequeña realizada con un matorral del mismo nombre.

PORTAL. Acceso a la vivienda ubicado dentro del corral. Zona estancial donde se realizaban los solanos.

PORTALADA. Puerta de acceso al corral para el carro o el ganado. Normalmente la "puerta de fuera" está enmarcada dentro de aquella.

PRADO o "PRAO". Parcela cercada con pared de piedra muy próxima a la vivienda de propiedad particular, destinada a "verde" para el ganado.

POSTIGO. Puertas de entrada a la vivienda.

"PUERTA DE FUERA". Puerta de acceso al corral para paso de personas.

RASPADERA. Rastrillo metálico para raspar el suelo de la era una vez realizada la trilla.

RASTROJO. Pajas cortas que quedan en la tierra después de la siega.

RAYA. Límite de un término municipal, provincia o nación en este caso Portugal.

RAYANO. Que limita con (término, provincia o nación).

REGATO. Arroyo pequeño o con muy poco caudal.

RIVERA. Ribera. Dialecto leonés.

RODILLO. Prado sin cercar ubicado en las tierras abiertas y cuyos pastos se aprovechan generalmente por el común de vecinos.

TENADA. Construcción auxiliar para guardar leña o guarecer al ganado.

TESO. Cerro. Cueto. Superficie elevada de terreno 
TORNADERA. Rastrillo de madera de picos redondeados ejecutado en una sola pieza que sirve para "esgarrar" los haces de I as "parvas" antes y durante el proceso de la trilla.

SOBRADO o "SOBRAO". Segunda planta ubicada sobre la vivienda para almacenamiento de cereal, legumbres, hortalizas, etc.

SUELO. Las parcelaciones que permiten cultivar privadamente en el cortineo, en las "tierras abiertas" o en la dehesa.

TORNO. Parte del arado que sirve para hacer los "cerros" más o menos grandes.

TRILLAR. Separar el grano de la mies.

VALLE. Zona incultivada para pastos ubicada entre tierras de labor.

VASAR o VASAL. Despensa situada al fondo de la vivienda.

VUELO. Todas las especies vegetales, árboles y los pastos de propiedad comunal.

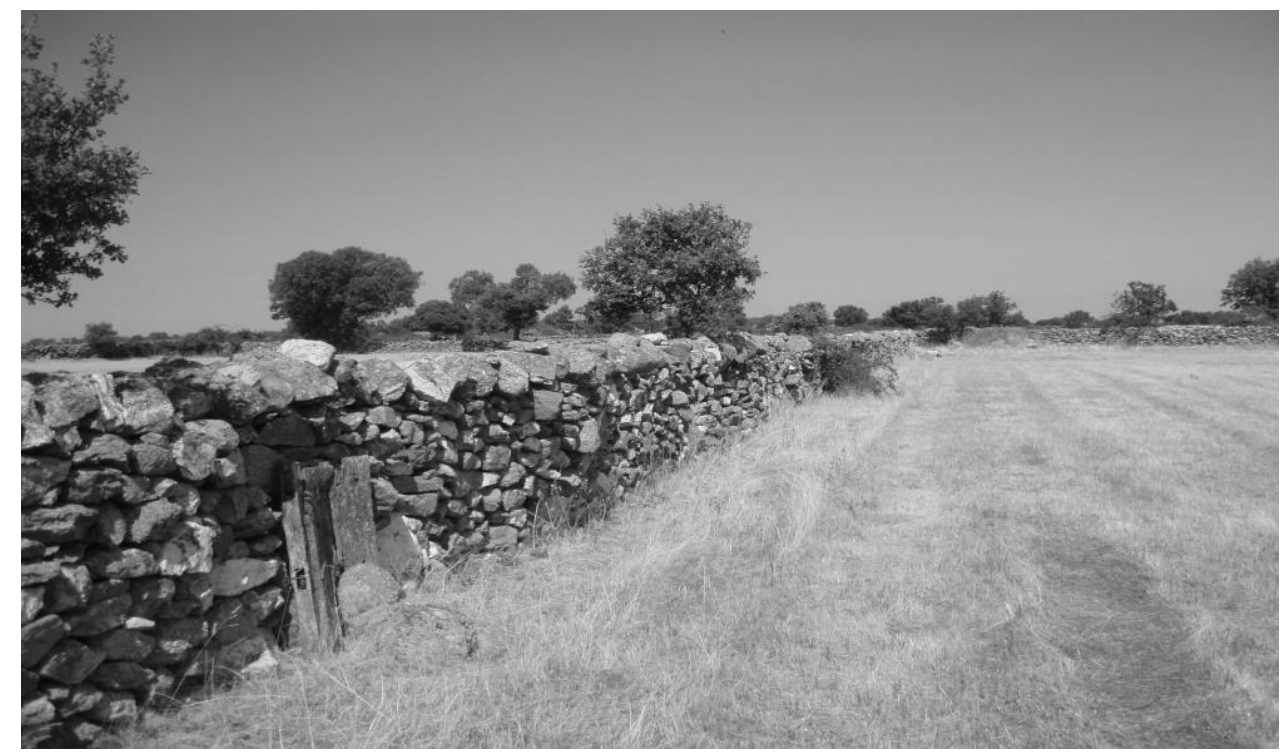

Imagen: Paisaje de cortinas.

\section{BIBLIOGRAFÍA}

García-Bellido y García de Diego (2004). "Evolución de los conceptos, teorías y neologismos cerdianos en torno a la urbanización". Ciudad y Territorio, serie monografías. "Cerdá y su influjo en los ensanches de poblaciones". Ministerio de Fomento. Dirección General de la Vivienda, la Arquitectura y el Urbanismo. Madrid.

(2005). Presentación de Aventuras y desventuras etimológicas de Cerdá en torno a su «Indicador urbano» de la urbanización. Ciudad y Territorio núm. 144. Ministerio de Vivienda. Madrid.

Prada Llorente, Esther (2005). Paisaje agrario: antropología de un territorio. Ciudad y Territorio núm. 144. Ministerio de Vivienda. Madrid. 